days in a high volume comprehensive stroke center between January 2017 and January 2020. Pre thrombectomy risk factors evaluated include age, NIHSS, ASPECT score, baseline mRS, occlusion site, and IV tPA administration. Post-thrombectomy risk factors include ASPECT score at 24 hours, TICI score, post-procedural subarachnoid hemorrhage (SAH), hemorrhagic transformation, and decompressive craniectomy. Procedural risk factors included the mode of anesthesia, intraprocedural systolic (SBP), diastolic (DBP), and mean arterial pressure (MAP) were reviewed as well as procedural blood pressure variability. The difference between the highest and lowest recorded blood pressure was defined as procedural variability.

Results Mechanical thrombectomy was performed in 290 patients, and 54 patients $(54 / 290,18.6 \%)$ were expired at 90 days, which include 42 anterior $(77.8 \%)$ and 22 posterior circulation patients (22.2\%). In 42 anterior circulation acute ischemic stroke patients who expired $(\mathrm{M}: \mathrm{F}=25: 17)$, the mean age was $77.5 \pm 13$, and $42.86 \%$ was at or more than 80 years old. Baseline estimated mRS three or above were seen in $92.7 \%$. The number of days from admission to decease was 7 (median). Pre-procedural ASPECT score $>6$ was noted in 32 patients $(32 / 42,76.19 \%)$ but in 11 patients $(11 / 42$, $26.19 \%)$ on post-procedure ASPECT at 24 hours. MCA, ICA and CCA occlusion was found in $69.05 \%, 19.5 \%$, and $9.52 \%$, respectively. Pre thrombectomy IV tPA was administered in 17 patients $(17 / 42,40.48 \%)$. TICI $2 \mathrm{~b}$ or three were achieved in $54.7 \%$, with the median number of passes were 2 . Ten patients (23.81\%) developed post thrombectomy symptomatic intracranial hemorrhages (sICH), and the hemorrhagic transformation was seen in $14.29 \%(n=6)$. Three patients $(7.14 \%)$ received decompressive craniectomy. Mean 'arrival to groin puncture time' and 'groin to reperfusion time' were $1.13 \pm$ 0.19 hours and 1 hour \pm 0.042 , respectively. Monitored Anesthesia Care $(n=29,69.04 \%)$ was used for most of the procedure. Mean procedural variability of MAP, DBP and SBP were $24.32+23.79 \mathrm{mmHg}, 16.38 \pm 24.83 \mathrm{mmHg}$, and $40.19 \pm 26.83 \mathrm{mmHg}$, respectively.

Conclusion Older age, low baseline estimated mRS, the relatively lower rate of successful reperfusion, the higher rate of $\mathrm{sICH}$, delayed groin to reperfusion time, and higher intraprocedural variability in MAP and DBP were observed in patients with mortality in our study.

Disclosures A. Toma: None. A. Vijayashankar: None. N. Haranhalli: None. R. Zampolin: None. D. Altschul: None. A. Brook: None. S. Lee: None.

\section{E-081 ENDOVASCULAR THROMBECTOMY FOR STROKE IN ELDERLY PATIENTS: A COMPREHENSIVE MULTICENTER ANALYSIS - INSIGHTS FROM THE STAR COLLABORATION}

${ }^{1} \mathrm{R}$ Chalhoub*, ${ }^{2} \mathrm{~A}$ Alawieh, ${ }^{1} \mathrm{~S}$ Kasab, ${ }^{1} \mathrm{D}$ Pullmann, ${ }^{3} \mathrm{~A}$ Arthur, ${ }^{4} \mathrm{~J} \mathrm{Kim},{ }^{5} \mathrm{R}$ De Leacy, ${ }^{6} \mathrm{M}$ Psychogios, ${ }^{7}$ I Maier, ${ }^{8} \mathrm{~A}$ Rai, ${ }^{9} \mathrm{~S}$ Keyrouz, ${ }^{10} \mathrm{~K}$ Fargen, ${ }^{11} \mathrm{R}$ Starke, ${ }^{1} \mathrm{~A}$ Spiotta. ${ }^{1}$ Neurosurgery, Medical University of South Carolina, Charleston, SC; ${ }^{2}$ Neurosurgery, Emory University, Atlanta, GA; ${ }^{3}$ Neurosurgery, The University of Tennessee Health Science Center, Memphis, TN; ${ }^{4}$ Neurosurgery, Chonnam National University Hospital, Donggu Gwangju, Korea, Republic of; ${ }^{5}$ Neurosurgery, Medical University of South Carolina, New Yotk, NY; ${ }^{6}$ Neuroradiology, University Hospital Basel, Basel, Switzerland; ${ }^{7}$ Neurology, Universitätsmedizin Göttingen, Göttingen, Germany; ${ }^{8}$ Neuroradiology, West Virginia University, Morgantown, WV; ${ }^{9}$ Neurology, Washington University in St. Louis, St Louis, MO; ${ }^{10}$ Neurosurgery, Wake Forest Baptist Health, Winston-Salem, NC; ${ }^{11}$ Neurosurgery, University of Miami Health System, Miami, FL

10.1136/neurintsurg-2020-SNIS.115
Introduction Acute ischemic strokes (AIS) due to large vessel occlusion (LVO) occur more frequently in elderly patients, resulting in more severe symptoms and worse outcomes after treatment. The purpose of this study is to evaluate the agedependent outcomes of Endovascular Thrombectomy (ET) in the real world, using a large dataset from the Stroke Thrombectomy and Aneurysm Registry (STAR).

Methods All patients undergoing endovascular thrombectomy for AIS at 12 comprehensive stroke centers between January 2013 and December 2018 were included. Data were retrospectively collected by reviewing patient charts and procedure notes. The primary endpoint was the modified Rankin Score (mRS) at 90-days after the procedure, which was dichotomized into good outcome (mRS $0-2$ ) or poor outcome (mRS 3-6).

Results Out of the 3850 patients that underwent mechanical

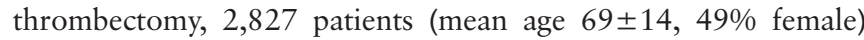
had 90-day follow-up and were included in this study. When adjusting for confounding variables using multivariate logistic regressions, increased age was found to be an independent predictor of poor outcome $(\mathrm{OR}=1.4, \mathrm{p}<0.001)$ and mortality $(\mathrm{OR}=1.5, \mathrm{p}<0.001)$. An age increment of 10 years was associated with $23 \%$ higher odds of symptomatic hemorrhage, and $50 \%$ higher odds of mRS 5-6. Predictors of good outcome in elderly population ( $\geq 80$ years) included higher ASPECT score $(\mathrm{aOR}=1.417, \mathrm{p}=0.02)$, lower admission NIHSS $(\mathrm{aOR}=0.892$, $\mathrm{p}<0.001)$, and lower number of attempts $(\mathrm{aOR}=0.664$, $\mathrm{p}=0.003$ ). The final Thrombolysis in Cerebral Infarction (TICI) score was associated with increased odds of better outcome in younger population $(\mathrm{aOR}=1.55, \mathrm{p}<0.001)$, but not in the elderly $(\mathrm{p}=0.329)$.

Conclusion Higher age is an independent predictor of worse outcome and increased mortality in patients undergoing ET for AIS. Baseline deficits, ASPECT score, and number of attempts, but not complete revascularization rates, were associated with better outcomes in elderly patients. Our findings underline the need for further refinement of selection criteria for elderly patients being considered for ET.

Disclosures R. Chalhoub: None. A. Alawieh: None. S. Kasab: None. D. Pullmann: None. A. Arthur: None. J. Kim: None. R. De Leacy: None. M. Psychogios: None. I. Maier: 6; C; Microvention, Cerenovus. A. Rai: 6; C; Stryker Neurovascular, Microvention, Cerenovus. S. Keyrouz: 6; C; PORTOLA. K. Fargen: 6; C; Cerebrotech Medical. R. Starke: 1; C; NREF, Joe Niekro Foundation, Brain Aneurysm Foundation, BEE Aneurysm Foundation, NIH. 6; C; Penumbra, Medtronic, Cerenovus, InNeuroCo, Abbott. A. Spiotta: 1; C; Penumbra. 6; C; Penumbra, Cerenovus.

\section{E-082 ANALYSIS OF COLLATERALS PROFILE AND SUCCESSFUL FIRST PASS THROMBECTOMY IN THE ELDERLY POPULATION: A SINGLE-CENTER EXPERIENCE}

A Monteiro*, G Cortez, Y Murtaza, A Aghaebrahim, E Sauvageau, R Hanel. Neurosurgery, Baptist Health System- Jacksonville, Jacksonville, FL

\subsection{6/neurintsurg-2020-SNIS. 116}

Introduction Patients over 80 years old account for one third ischemic strokes in the developed world, with an overall poor outcome. Although current guidelines do not recommend an upper age limit for endovascular approach, the benefit in the elderly population is still uncertain. In spite of 
efforts to identify criteria associated with good outcomes in this age range, literature has not found any yet. We aimed to use novel tools being reported in stroke literature, such as First Pass Effect (FPE) and Hypoperfusion Intensity Ratio (HIR), to optimize elderly patient selection for thrombectomy.

Methods A single-center retrospective analysis of a prospectively maintained large vessel occlusion database (20142019) was conducted. We included patients $\geq 80$ years old with acute ischemic stroke that underwent endovascular thrombectomy. First pass thrombectomy was defined as single attempt obtaining TICI $2 \mathrm{~b}$ or higher without distal embolization, as previously stated in literature. Collaterals were assessed based on HIR (good collaterals <0.4; poor collaterals $\geq 0.4$ ). Baseline characteristics, procedural data, and outcomes were evaluated. The association between clinical and procedural variables and outcomes at 90 days was assessed.

Results A total 146 patients were included in the study. Mean age was $87.8 \pm 4.12$ (range $80-100$ ) and $65.75 \%$ were female. Pre-stroke functional independence (baseline mRS 02) was seen in $64.1 \%$. Median time of onset to groin puncture was 261.5 minutes and mean time from groin puncture to recanalization was 37.15 minutes. Good collaterals were seen in $50.9 \%$ of patients. Successful reperfusion (TICI $2 \mathrm{~b}$ or higher) was achieved in $87.1 \%$. The rates of good outcome (mRS 0-2), acceptable outcome (mRS 0-3) and poor outcome (mRS 4-6) at 90 days were $18.5 \%, 38.1 \%$ and $43.4 \%$, respectively. Multivariate logistic regression indicated that pre-stroke functional independence $(p=0.0008)$, good collaterals $(p=0.0009)$, use of stent retriever (Solitaire, $p=0.035$; Trevo, $p=0.032)$ and balloon guide catheter $(p=0.028)$ were associated with good outcome.

Conclusions In our retrospective cohort of elderly patients treated with thrombectomy, the baseline characteristics that appear to influence in the rate of good outcome were the pre-stroke functional independence and the presence of good collaterals. Although previous studies with younger populations showed promising use of First Pass Effect measure to predict good outcome in patients who underwent thrombectomy, we did not find any significant association in patients $\geq 80$-yearold. Preference for the use of stent-retriever and balloon guide-catheter may shorten the time to reperfusion and therefore, provide better outcomes. We emphasize the need of further studies to improve selection criteria for endovascular thrombectomy in this population.

Disclosures A. Monteiro: None. G. Cortez: None. Y. Murtaza: None. A. Aghaebrahim: None. E. Sauvageau: None. R. Hanel: 2; C; Microvention, Codman, Stryker, Medtronic.

\section{E-083 A QUANTITATIVE AND QUALITATIVE ANALYSIS OF \#RADIALFIRST CONVERSATIONS ON TWITTER}

N Alotaibi* ${ }^{*}$ P Harker, F Robertson, J Vranic, M Koch, C Stapleton, T Leslie-Mazwi, A Patel. Neurosurgery, Massachusetts General Hospital, BOSTON, MA

10.1136/neurintsurg-2020-SNIS.117 